\title{
Amoebic liver abscess draining into the bile ducts
}

\author{
R. L. VIANA ${ }^{1}$ \\ From the Medical Research Institute, Department of Medicine, \\ Lourenzo Marques, Mozambique
}

EDITORIAL SYNOPSIS The author describes the drainage of two amoebic abscesses into the biliary tract. This can be demonstrated radiologically and perhaps would be a worthwhile investigation in patients with hepatic abscesses as it might avoid surgical exploration or multiple aspirations.

According to reports in the literature the spontaneous drainage of an amoebic abscess of the liver into the biliary tree is a very rare event (Bowers and Barnes, 1960; Boquien and Lenne, 1962; Craig, 1934), and it may account for the rapid and complete recovery in a few cases within a few hours of starting anti-amoebic therapy. In this paper we describe two such cases.

\section{CASE HISTORIES}

CASE 1 A 19-year-old Bantu man was admitted to Miguel Bombarda Hospital on 3 December 1963. Mild, vague, upper abdominal pain had commenced one month earlier and was associated with chills and fever, generalized malaise, weakness and weight loss. Two weeks later a slight bulge appeared in the right upper quadrant. His symptoms increased in severity and jaundice appeared; there was no nausea or vomiting and his stools were normal.

On examination he was thin, jaundiced and ill. The temperature on admission was $38.8^{\circ} \mathrm{C}$. and blood pressure $110 / 70 \mathrm{~mm}$. $\mathrm{Hg}$. There was a visible swelling in the right upper quadrant of the abdomen with slight oedema of the overlying skin. The liver was enlarged $9 \mathrm{~cm}$. below the right costal margin. Examination of the chest showed the right diaphragm to be elevated. There was a previous history of schistosomiasis and chronic alcoholism.

Investigations Haemoglobin was $12.2 \mathrm{~g} . / 100 \mathrm{ml}$.; white cell count was 8,550 (neutrophils $74 \%$, lymphocytes $23 \%$, eosinophils $2 \%$, myelocytes $1 \%$ ); the erythrocyte sedimentation rate was 105 in one hour (Wintrobe). Alkaline phosphatase level was 4 Bodansky units; serum total bilirubin $3.9 \mathrm{mg} . / 100 \mathrm{ml}$.; conjugated bilirubin $1.6 \mathrm{mg} . / 100 \mathrm{ml}$. Prothrombin index was $48 \%$ of normal. Bromsulphalein test gave $18 \%$ retention at 45 minutes. Glutamic oxaloacetic transaminase level was 120 Karman units (normal 20 to 25 ) and glutamic pyruvic transaminase 83 Karman units (normal 20 to 25). Sigmoidoscopy showed no abnormality. In the urine were ova of Schistosoma haematobium and in the faeces

${ }^{1}$ Present address: Medical Unit, Royal Free Hospital, London, W.C.1 numerous ova of $A$. lumbricoides and a few ova of $T$. trichiura and $E$. vermicularis.

A diagnosis of amoebic hepatic abscess was made. Exploratory puncture of the liver produced $25 \mathrm{ml}$. of thick 'anchovy sauce' pus in which no amoebae were found. Per Abrodil (Bayer) 45\% contrast medium was injected into the abscess to determine the size and the position of the cavity (Lieske and Buck, 1963) and a radiograph taken half an hour later, but most of the contrast was found in the small bowel and the cavity of

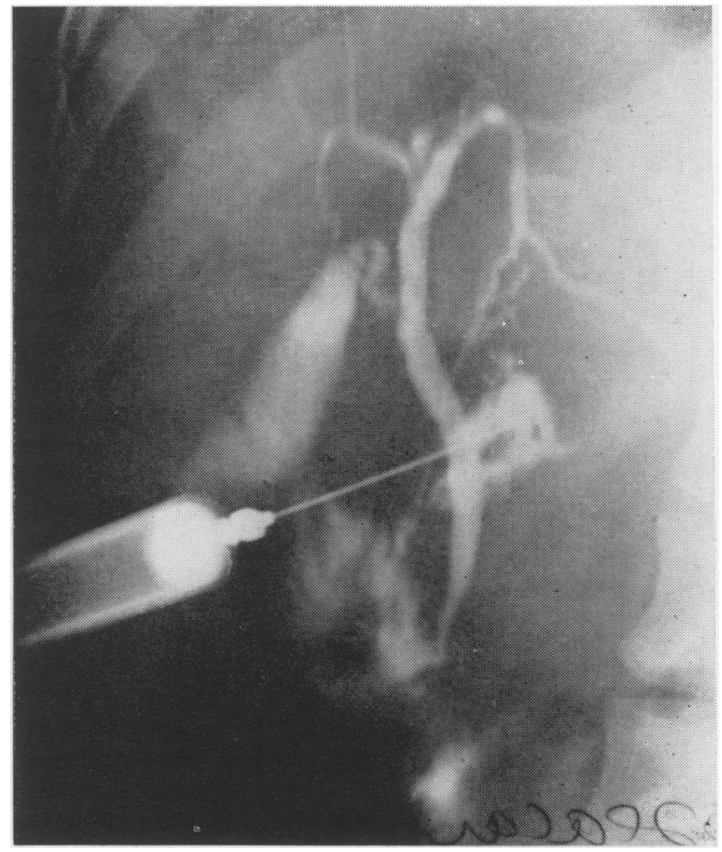

FIG. 1. The cavity of the abscess connects with the common bile duct through a narrow tract and produces retrograde filling of the biliary tree. The duodenum also contains contrast. 
the abscess was not seen. Another $10 \mathrm{ml}$. of pus was aspirated and more contrast medium $(10 \mathrm{ml}$.) was injected under fluoroscopic control. During the injection of the contrast medium the small cavity of the abscess was seen to fill and drain through a narrow tract into the lower common bile duct. Retrograde filling of the biliary tree then occurred and finally the contrast appeared in the duodenum (Fig. 1).

The patient was treated with chloroquine, $0.6 \mathrm{~g}$. daily, for three weeks and $125 \mathrm{mg}$. oxytetracycline was injected into the cavity. Within three days the patient was feeling much better and had no pain. After eight days the swelling in the anterior abdominal wall had disappeared and liver function tests were normal.

CASE 2 A Bantu, aged 26, attended Miguel Bombarda Hospital on 9 January 1964. For two months before admission he had had generalized pain, chills, fever, and diarrhoea. The pain became localized to the right upper quadrant where there was a marked abdominal swelling.

On admission he was in severe pain and looked ill with a temperature of $38^{\circ} \mathrm{C}$. There was a large mass on the right side of the abdomen with overlying oedema of the skin. The liver was enlarged $9 \mathrm{~cm}$. below the right costal margin.

Investigations Haemoglobin was $11 \mathrm{~g} . / 100 \mathrm{ml}$.; white cell count was 6,650 per c.mm. (neutrophils $48 \%$, lymphocytes $43 \%$, eosinophils $9 \%$, basophils $6 \%$ ); erythrocyte sedimentation rate was $90 \mathrm{~mm}$. in one hour (Wintrobe). The total serum bilirubin was $0.5 \mathrm{mg}$./

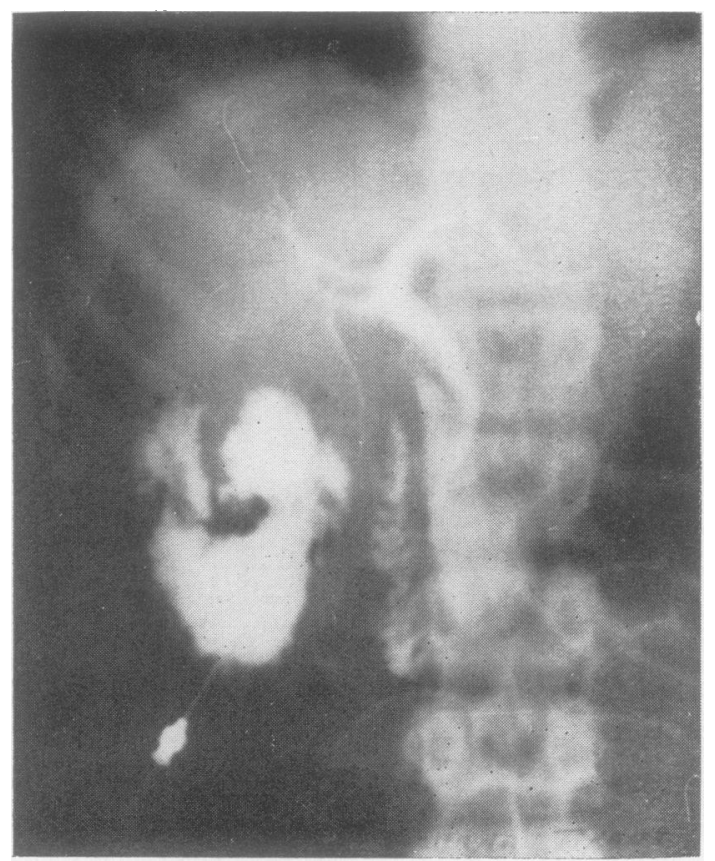

FIG. 2. Large abscess cavity draining into the right hepatic duct through narrow bile ducts.
$100 \mathrm{ml}$. The bromsulphalein test showed $4 \%$ retention at 45 minutes. Glutamic oxaloacetic transaminase was 52 Karman units (normal 20 to 25 ) and glutamic pyruvic transaminase 24 Karman units (normal 20 to 25); alkaline phosphatase $2 \cdot 7$ Bodansky units. Urine was normal but in the faeces ova of $T$. trichiura and $A$. lumbricoides were found. Sigmoidoscopy was normal. Fluoroscopy of the chest showed no elevation of the diaphragm.

A diagnosis of amoebic abscess was made. On needle aspiration, $30 \mathrm{ml}$. of 'anchovy sauce' pus was obtained, but $E$. histolytica was not found. Under fluoroscopic control $30 \mathrm{ml}$. of contrast medium was injected into the cavity of the abscess, when a large cavity of irregular outline was seen to fill and to drain through narrow channels into the right hepatic duct (Fig. 2).

Anti-amoebic treatment was given, $0.6 \mathrm{~g}$. chloroquine per day, and $125 \mathrm{mg}$. oxytetracycline was injected into the cavity of the abscess after aspiration of $700 \mathrm{ml}$. of pus. Three days later the patient discharged himself from hospital against medical advice.

\section{DISCUSSION}

Every patient who presents with weakness, fever, right upper quadrant abdominal pain, and hepatomegaly should be suspected of having an amoebic abscess of the liver. A moderate leucocytosis and elevation of the right diaphragm are of the value in establishing the diagnosis, but complete confirmation can be made only by aspiration of characteristic 'anchovy sauce' pus and by a full response to antiamoebic therapy. Examination of pus for E. histolytica gives negative results in most cases because the amoebae are localized in the deeper layers of the abscess wall. The liver function tests are rarely altered and are therefore of value in differential diagnosis. A few workers (Viranuvatti, Harinasuta, Plengvanit, Choungchareon, and Viranuvalti, 1962) have however emphasized abnormalities of the bromsulphalein test and alkaline phosphatase values in amoebic hepatic abscess.

Both our patients had hepatomegaly, fever, and marked right upper quadrant pain. In our first case we found bilirubin and transaminase levels increased and the bromsulphalein test was abnormal. The second patient also had an elevated level of S.G.O.T. It seems likely that the abnormalities in both cases were due to the considerable inflammatory reaction around the large abscess.

Many workers (Craig, 1934; Ude, 1928; Bowers and Barnes, 1960; Tillman and Galambos, 1960) state that the rupture of an amoebic hepatic abscess into the bile ducts is very uncommon, and, according to Boquien (Boquien and Lenne, 1962) spontaneous rupture is also rare. However, these two cases were found in the first 15 patients in whom amoebic abscess was visualized with contrast 
medium under fluoroscopic control, so that it cannot be rare.

In the first case fluoroscopy showed that the abscess had ruptured through a narrow tract into the lower common bile duct. In the second the abscess drained through narrow bile ducts into the right hepatic duct.

The routine use of contrast medium to visualize amoebic liver abscess under fluoroscopic control will result in the diagnosis of many more cases of amoebic abscess draining into the biliary tree. This finding will guide therapy in such a way as to prevent unnecessary multiple punctures or surgical drainage.

In most instances the prognosis of hepatic amoebic abscess is good with conservative therapy. However, it depends on several factors, including the virulence of the agent, the degree of hepatic involvement, the presence of pleuropulmonary or pericardial infection, and rupture into the peritoneal cavity. Surgical drainage is seldom necessary and is best avoided because of the risk of secondary infection. Furthermore surgical drainage often leads to amoebic invasion of the skin around the drainage tube producing ulceration of the abdominal wall.

\section{REFERENCES}

Bowers, R. F., and Barnes, Z. B., Jr. (1960). Amebic abscess of the liver drained through the common duct: report of a case. Ann. Surg., 151, 465-468.

Boquien, Y., and Lenne, CI. (1962). La fistulisation des abcès amibiens du foie dans les voies biliaires. Cah. $R$. M. F. (Paris) 76, 281-286.

Craig, C. F. (1934). Amebiasis and Amebic Dysentery. Thomas, Springfield, Illinois.

Lieske, H. H., and Buck, A. A. (1963). Acerca da visualização radiologica dos abcessos hepáticos amibianos. com meios de contraste. Bayer. Ärztebl., 3, 51-57.

Tillman, S. P., and Galambos, J. T. (1960). Amebic abscess of the liver communicating with bile ducts. Amer. J. dig. Dis., 5, 807-814.

Ude, W. H. (1928). Liver abcess with roentgenologic demonstration of rupture into bile ducts. Amer. J. Roentgenol., 20, 527-528.

Viranuvatti, V., Harinasuta, T., Plengvanit, U., Choungchareon, P., and Viranuvalti, V. (1963). Liver function test in hepatic amebiasis, based on 274 clinical cases. Amer. J. Gastroent., 39, 345-361. 